Иветта Сергеева

\title{
МОРАЛЬНОЕ ПУТЕШЕСТВИЕ \\ СПЕЦИАЛИСТОВ СОЦИАЛЬНЫХ СЛУЖБ \\ В МИРЕ БЮРОКРАТИЧЕСКОГО РЕГУЛИРОВАНИЯ
}

\section{Zacka B. (2017) When the State Meets the Street: Public Service and Moral Agency. Cambridge, MA: Harvard University Press. 337 pp. ISBN 978067454550.}

\author{
DOI: $10.17323 / 727-0634-2020-18-3-550-554$
}

Несмотря на всепроникающую междисциплинарность в современном научном мире, политический теоретик, проводящий этнографическое исследование,- пока явление нечастое. Политические теоретики привычно критикуются за то, что увлекаются построением и анализом идеальных конструкций, таких как «закон», «бюрократия», «демократия», но, как правило, не выходят в поле разобраться, насколько их конструкции соответствуют реальной жизни. Бернардо Зака, исследователь из департамента политических наук Массачусетского технологического института (MIT), по собственному признанию, хорошо знаком с этой критикой и решил отнестись к ней со всей серьезностью (Р. 28). Его первая книга «Когда государство встречается с улицей: государственная служба и моральная агентность» основана на материалах собственного этнографического исследования, а также полевых материалах других этнографов, изучавших уличную бюрократию. Сам Зака провел в поле восемь месяцев, работая в качестве волонтера в некоммерческой организации, помогающей бедным в США.

Анализируя полученные в поле данные с помощью концепций политической теории и моральной философии, Зака пытается разобраться, как устроен институт бюрократии низового уровня (street-level bureaucracy). Его исследование фокусируется на том, что он называет нравственными установками (moral dispositions) и моральной агентностью (moral agency) уличных бюрократов. В то время как от бюрократов ожидается способность принимать нравственные решения, они поставлены в структурные условия, которые подрывают эту самую способность- такова одна из основных идей книги.

Бюрократы низового уровня- термин, получивший распространение благодаря Майклу Липски, исследователю MIT (Lipsky [1980] 2010), определяющего бюрократов низового уровня как государственных служащих, предоставляющих гражданам доступ к государственным программам

Иветта Сергеева- магистр политологии, студентка магистратуры, факультет социологии и философии; стажер-исследователь, Институт проблем правоприменения, Европейский университет в Санкт-Петербурге, Санкт-Петербург, Россия. Электронная почта: isergeeva@eu.spb.ru 
и оказывающих услуги в рамках этих программ. Типичные бюрократы низового уровня, по Липски, это судьи, учителя, полицейские, социальные работники. Вопреки теоретическим представлениям о бюрократах как пассивных технических исполнителях, они обладают весомой степенью автономности на принятие решений относительно дел граждан-дискрецией (например, выписать штраф или административное предупреждение, взять человека под арест или отпустить, одобрить выплату социального пособия или отказать). Работая в сложных условиях зачастую с запутанными и противоречащими друг другу требованиями и нехваткой времени и ресурсов, уличные бюрократы могут адаптироваться к ним, используя дискрецию особым, нередко предвзятым образом (например, при задержании на улице отдавать предпочтение людям определенной этничности чаще, чем другой). А это, в свою очередь, оказывает значительное влияние на жизнь конкретных людей и структуру оказания государственных услуг и предоставления общественных благ в целом. Так можно кратко описать некоторые из тех проблем, с которым работает Липски и его последователи.

В видении Зака, культура низовой бюрократии распространяется не только на государственных служащих, но и на сотрудников некоммерческих организаций (НКО). НКО стали «поставщиками государственных услуг» на волне реформ нового государственного управления (new public management) в 1980-2000 гг., поощрявших аутсорсинг государственных функций негосударственным исполнителям. Получив государственное финансирование на оказание услуг социальной поддержки, они оказались подконтрольны государству и переняли государственную организационную культуру. Это позволяет исследователю говорить о НКО как институте уличной бюрократии в такой же степени, как о госслужбе.

Так же, как и других исследователей уличной бюрократии, Зака интересует проблема дискреции. Он стремится сместить внимание с момента принятия решения на влияние структурных условий нравственных установок бюрократов. К нравственным установкам в книге относится «то, как они склонны воспринимать и интерпретировать ситуации и кейсы, как мобилизуются их нравственные чувства и как они понимают собственную роль и обязанности» (Р. 11). Зака определяет три типичных ориентации в нравственных установках бюрократов- индифферентный (the Indifferent), правоприменитель (the Enforcer) и заботящийся (the Caregiver). Каждая из них означает соскальзывание в определенный паттерн поведения в отношении обращающихся за помощью людей. Все установки до определенной степени «патологичны», поскольку лимитируют возможности бюрократов в том, как они понимают ситуации клиентов, как работают с ними и какие решения в отношении них принимают. Иными словами, эти установки подрывают способность бюрократов к осмысленному использованию дискреции. Такая ситуация во многом связана с адаптацией к противоречивым и конфликтующим требованиям 
к их работе. Однако Зака утверждает, что бюрократы способны использовать особые методики, чтобы не оказаться в одном из патологичных паттернов. Бюрократы Зака, таким образом, не пассивные участники процесса и не винтики в государственной машине, а агенты, до определенной степени осведомленные о проблематичности своей позиции и способные к ее преодолению. Эта перспектива критикует общий дух дискуссии о бюрократах низового уровня, который сказывается на существующем в исследованиях государственного управления пренебрежении к исполнителям государственных программ.

Оригинальность и драматичность книги, пожалуй, проявляется в ее последней, пятой главе. Именно она является ключевой по силе убедительности идей и соответствию первоначальной задумке автора- исследовать, каким образом условия труда бюрократов влияют на их нравственные установки. В ней Зака рассматривает три кейса низовых бюрократов, объединенных одной проблемой- невозможностью соответствовать требованиям эффективности. Для того чтобы проанализировать эти истории, автор вводит понятие «невыносимая ситуация» (impossible situation) - это ситуация такой степени напряжения между требованиями системы и собственным пониманием бюрократов своей роли, которое ведет к поломке агентности (agential breakdown). Для человека оказывается невозможным следовать требованиям системы и при этом продолжать быть хорошим учителем (социальным работником, полицейским, судьей) в собственном представлении. Это не классический конфликт социальных ролей (например, когда учитель должен учить собственного ребенка). Речь идет о конфликте нравственных миров и невозможности найти баланс внутри одной и той же роли, что приводит к уходу из организации, открытому конфликту с начальством, хроническому стрессу или другим подобным последствиям.

Зака сравнивает это положение с ситуацией «двойного послания». Это понятие впервые использовалось, чтобы описать коммуникативную ситуацию, в которой «невозможно выиграть, что бы человек не делал», предположительно способную вызвать симптомы шизофрении (Bateson et al. 1956). В дальнейшем двойное послание было распространено в гендерных и постколониальных исследованиях практик угнетения. Зака упоминает критическую природу понятия, но нельзя сказать, что делает свое исследование критическим по духу, используя его. Невыносимые ситуации и использование бюрократами ответных (более или менее патологичных) стратегий кооптирования - это в целом неизбежная, хоть и досадная часть процесса реализации государственных программ, считает он. Исследователь не поднимает вопросы, которые кажутся логичным продолжением этих размышлений: можем ли мы понять, слишком ли высоко напряжение «невозможных ситуаций» в системе государственного управления? До какой степени «невозможные ситуации» действительно неизбежны или они 
все же являются признаком плохого управления? Во введении книги автор удивляется тому, как печально мало знают высокопоставленные чиновники об операционных процессах на местах, хотя это их прямая обязанность. Неоднократно указывает, что высокий уровень выгорания уличных бюрократов- это тревожный симптом, однако не развивает проблему, не показывает, «как много невозможных ситуаций- это уже слишком много» и кто несет за это ответственность. Что было бы очень важным вкладом в дискуссию о качестве государственного управления.

Несмотря на сопереживание бюрократии, которое способна вызвать книга, легко понять, почему исследователи и практики считают бюрократизацию организаций третьего сектора проблемой (Ferguson 2007; Dustin 2016; Enjolras et al. 2018). Помимо прочих негативных следствий, иногда представляется, что бюрократы создают вокруг себя особый мир, в котором нет места человеческому взаимодействию. Сам Зака, в одном из своих публицистических эссе, дает яркую иллюстрацию. Однажды один из посетителей службы без особого повода обратился к нему, спросив, читал ли он в школе Хэмингуэя. Зака ответил, что Хэмингуэя не читал, но читал Стейнбека. Этот диалог описывается как отступление от традиционного скрипта работы в службе, важный, но редкий момент искреннего контакта бюрократа и посетителя (Zacka 2017). Читая книгу, я немало размышляла о том, насколько неизбежно обратное и должны ли мы смириться с естественностью механистической бюрократии? Возможно, возрастающий интерес к исследованиям взаимодействий гражданина и государства поможет ответить на эти вопрос.

Книга будет интересна исследователям государства, социальной политики и НКО. Ее найдут примечательной и теоретики, и эмпирики. Автору удалось решить непростую задачу- схватить живой этнографический материал рамками политической теории. Если верить персональному сайту автора, его следующая книга будет посвящена влиянию архитектуры пространства социальных служб на практики их работы. Опыт прочтения первой книги заставляет с интересом ожидать вторую. 
Ivetta Sergeeva

THE MORAL QUEST OF SOCIAL SERVICE PROFESSIONALS IN THE WORLD OF BUREAUCRATIC REGULATION

\section{Zacka B. (2017) When the State Meets the Street: Public Service and Moral Agency. Cambridge, MA: Harvard University Press. 337 pp. ISBN 978067454550.}

DOI: $10.17323 / 727-0634-2020-18-3-550-554$

\section{References}

Bateson G., Jackson D. D., Haley J., Weakland J. (1956) Toward a Theory of Schizophrenia. Behavioral science, 1 (4): 251-264.

Dustin D. (2016) The McDonaldization of Social Work. New York: Routledge.

Enjolras B., Salamon L., Sivesind K. H., Zimmer A. (2018) The Third Sector as a Renewable Resource for Europe: Concepts, Impacts, Challenges and Opportunities. Cham: Palgrave Macmillan.

Ferguson I. (2007) Reclaiming Social Work: Challenging Neo-liberalism and Promoting Social Justice. Thousand Oaks: Sage.

Lipsky M. (2010) Street-level Bureaucracy: Dilemmas of the Individual in Public Service. New York: Russell Sage Foundation.

Zacka B. (2017) Why Bureaucrats Don't Seem to Care. A Researcher's Reflection on Eight Months of Observing Workers at an Anti-poverty Agency. The Atlantic, 12 October. Available at: https://www.theatlantic.com/business/archive/2017/10/bureaucrat-welfare-zacka/542547/ (accessed 21 December 2019).

Ivetta Sergeeva-MA Sci. (Pol.), MA student of Department of Sociology and Philosophy, The European University at St. Petersburg, St. Petersburg, Russian Federation. Email isergeeva@ eu.spb.ru 